\title{
Consistent Pulmonary Drug Delivery with Whole Lung Deposition Using the Aerosphere Inhaler: A Review of the Evidence
}

This article was published in the following Dove Press journal: International Journal of Chronic Obstructive Pulmonary Disease

\author{
Omar S Usmani $\mathbb{D D}^{\prime}$ \\ Nicolas Roche $\mathbb{D}^{2}$ \\ Martin Jenkins ${ }^{3}$ \\ Neda Stjepanovic (D) ${ }^{4}$ \\ Peter Mack $^{5}$ \\ Wilfried De Backer ${ }^{6}$ \\ 'National Heart and Lung Institute \\ (NHLI), Imperial College London, and \\ Royal Brompton Hospital, London, UK; \\ ${ }^{2}$ Respiratory Medicine, Cochin Hospital, \\ University Paris Descartes, Paris, France; \\ ${ }^{3}$ AstraZeneca, Cambridge, UK; \\ ${ }^{4}$ AstraZeneca, Gothenburg, Mölndal, \\ Sweden; ${ }^{5}$ AstraZeneca, Durham, NC, \\ USA; ${ }^{6}$ Department of Pulmonary \\ Medicine, Faculty of Medicine, University \\ of Antwerp, Antwerp, Belgium
}

\begin{abstract}
Metered dose inhalers (MDIs) are one of the most common device types for delivering inhaled therapies. However, there are several technical challenges in development and drug delivery of these medications. In particular, suspension-based MDIs are susceptible to suspension heterogeneity, in vitro drug-drug interactions, and patient handling errors, which may all affect drug delivery. To overcome these challenges, new formulation approaches are required. The Aerosphere ${ }^{\mathrm{TM}}$ inhaler, formulated using cosuspension delivery technology, combines drug crystals with porous phospholipid particles to create stable, homogenous suspensions that dissolve once they reach the airways. Two combination therapies using this technology have been developed for the treatment of COPD: glycopyrrolate/formoterol fumarate (GFF MDI; dual combination) and budesonide/glycopyrrolate/formoterol fumarate (BGF MDI; triple combination). Here, we review the evidence with a focus on studies assessing dose delivery, lung deposition, and effects on airway geometry. In vitro assessments have demonstrated that the Aerosphere inhaler provides consistent dose delivery, even in the presence of simulated patient handling errors. Combination therapies delivered with this technology also show a consistent fine particle fraction (FPF) and an optimal particle size distribution for delivery to the central and peripheral airways even when multiple drugs are delivered via the same inhaler. Studies using gamma scintigraphy and functional respiratory imaging have demonstrated that GFF MDI is effectively deposited in the central and peripheral airways, and provides clinically meaningful benefits on airway volume and resistance throughout the lung. Overall, studies suggest that the Aerosphere inhaler, formulated using co-suspension delivery technology, may offer advantages over traditional formulations, including consistent delivery of multiple components across patient handling conditions, optimal particle size and FPF, and effective delivery to the central and peripheral airways. Future studies may provide additional evidence to further characterize the clinical benefits of these technical improvements in MDI drug delivery.
\end{abstract}

Keywords: Aerosphere, BGF MDI, co-suspension delivery technology, FRI, GFF MDI, metered dose inhaler

\section{Background}

Respiratory conditions including COPD and asthma are typically treated with inhaled therapies including short- or long-acting bronchodilators and inhaled corticosteroids (ICS). ${ }^{1,2}$ These treatments can be delivered using a variety of devices including pressurized metered dose inhalers (pMDIs), dry powder inhalers (DPIs), soft mist inhalers (SMIs), and nebulizers. ${ }^{1,3}$ Regardless of the inhaler type used, handling
Department of Pulmonary Medicine,

Faculty of Medicine, University of

Antwerp, Lange Lozanastraat 142

Antwerp 2018, Belgium

Tel +32468195206

Email wilfried.debacker@uantwerpen.be
International Journal of Chronic Obstructive Pulmonary Disease 2021:|6 || 3-124 
errors are common. ${ }^{4-6}$ Patients with COPD or asthma who are elderly, using multiple device types, or lacking education in proper device use often display poor inhaler technique, ${ }^{7,8}$ which is associated with reduced symptom control and increased risk of exacerbations. ${ }^{4,7,9}$ The efficiency of pulmonary drug delivery from inhaler devices may also depend on characteristics of the formulation, including the fine particle fraction (FPF; the fraction of the dose that is delivered from the device at a particle size appropriate for lung delivery), the mass median aerodynamic diameter (MMAD) of the drug particles, and the particle size distribution. ${ }^{10,11}$ Additionally, both total lung deposition as well as regional deposition may impact the effectiveness of drug delivery. ${ }^{12,13}$ Thus, it is important to optimize these characteristics to ensure that patients receive a consistent benefit from their inhaled medications.

The MDI is one of the most common inhaler types, representing approximately $70 \%$ of short-acting bronchodilator prescriptions and $27 \%$ of maintenance treatment prescriptions for COPD based on a real-world database study of US clinical practice from 2014 to $2017 .{ }^{14}$ Depending on patient needs, they can be dosed with or without a valved holding chamber or spacer, and are also available in breath-actuated devices. ${ }^{15}$ MDIs are formulated as either a solution or suspension (more common) of drug crystals in a hydrofluoroalkane propellant, which generates the energy required for drug aerosolization when the canister is pressed into the actuator. ${ }^{16,17}$ Suspension MDI formulations are often unstable, and the agglomeration of drug crystals can cause creaming or sedimentation within the canister. This may result in variation in the dose delivered from the inhaler. ${ }^{17}$ To avoid this, suspension MDIs must be shaken immediately before use.

For patients with COPD who experience persistent symptoms or exacerbations on single bronchodilator therapy, the addition of a second bronchodilator and/or an ICS is a recommended treatment option. ${ }^{1}$ Fixed-dose combinations (FDCs) containing two or three therapies in a single inhaler have been developed to simplify patients' treatment regimens. This single inhaler approach presents additional formulation challenges, as drug combinations may not have equivalent performance to the individual components, due to in vitro drug-drug interactions in the co-formulation. ${ }^{18,19}$ These co-formulation effects can result in inconsistent drug delivery, or disparate FPFs or particle size distributions of the individual components. ${ }^{17}$

Various technical approaches have been developed to overcome these challenges in MDI formulation and thereby improve drug delivery, including the innovative
Aerosphere $^{\mathrm{TM}}$ inhaler, an MDI formulated using cosuspension delivery technology. ${ }^{18}$ Here, we present a narrative review of the current literature characterizing this technology, with a focus on studies assessing dose delivery, lung deposition, and airway response.

\section{What is Co-Suspension Delivery Technology?}

Co-suspension delivery technology is an MDI formulation approach whereby drug crystals are co-suspended with porous phospholipid particles. $^{18,20}$ As phospholipids are an endogenous component of lung surfactant, they are biocompatible and well tolerated by the airways when used for inhaled drug delivery. ${ }^{21}$ The porous particles have a foam nanostructure that assists with aerosolization, and an amphiphilic corrugated surface that allows strong, non-specific associations between the drug crystals and particles that persist even after the device is actuated. ${ }^{20}$ In addition, there is no requirement for co-solvents and surfactants, as the strong, non-specific association between the porous phospholipid particles and the drug crystals spontaneously forms a slowly-creaming, stable suspension in the hydrofluoroalkane propellant. ${ }^{18}$ These characteristics reduce co-formulation effects and result in consistent delivery of multiple drugs from the same device, with improved stability and homogeneity versus drug crystal-only suspensions. The porous particles dissolve when they reach the airways, releasing the drug into the mucosal surface, as they are composed of the phospholipid distearoylphosphatidylcholine and calcium chloride, both naturally occurring compounds in the lungs. ${ }^{18}$

The co-suspension delivery technology used in the Aerosphere inhaler has been designed for use across different drugs and drug combinations (monotherapies, dual therapies, and triple therapies), at a range of doses for inhaled therapy (Figure 1). Dual and triple fixed-dose combinations formulated using this technology have been shown to deliver similar FPFs, MMADs, and particle size distributions of all components within the combination inhalers. ${ }^{20}$ The potential clinical benefits of these technical advancements in MDI formulation are summarized in Table 1.

Thus far, two FDC therapies have been developed using co-suspension delivery technology: a dual combination longacting muscarinic antagonist (LAMA)/long-acting $\beta_{2^{-}}$ 


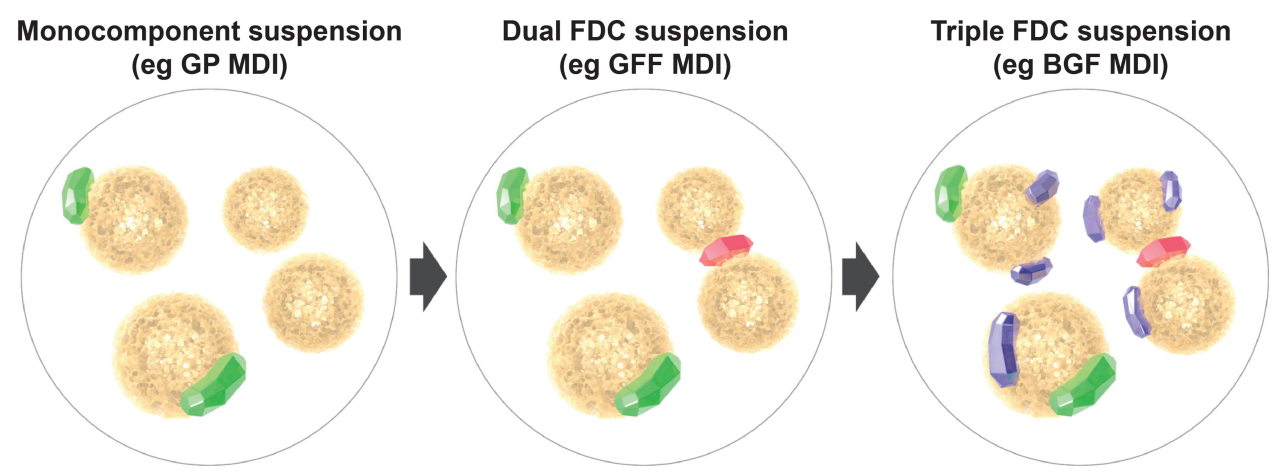

Spray-dried phospholipid/ $\mathrm{CaCl}_{2}$ porous particle

\section{LAMA crystal}
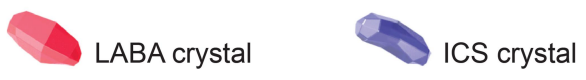

Figure I Overview of co-suspension delivery technology, as used in the Aerosphere inhaler. Reproduced with permission from Rabe KF, GFF MDI for the improvement of lung function in COPD - A look at the PINNACLE-I and PINNACLE-2 data and beyond, Expert Review of Clinical Pharmacology, 2017; Rights managed by Taylor \& Francis Ltd. ${ }^{57}$ Abbreviations: BGF, budesonide/glycopyrrolate/formoterol fumarate; $\mathrm{CaCl}_{2}$, calcium chloride; FDC, fixed-dose combination; GFF, glycopyrrolate/formoterol fumarate; GP, glycopyrrolate; ICS, inhaled corticosteroid; LABA, long-acting $\beta_{2}$-agonist; LAMA, long-acting muscarinic antagonist; MDI, metered dose inhaler.

agonist (LABA), glycopyrrolate/formoterol fumarate (GFF) MDI (BEVESPI AEROSPHERE $\left.{ }^{\circledR}\right)$, and a triple combination ICS/LAMA/LABA, budesonide/glycopyrrolate/formoterol fumarate (BGF) MDI (BREZTRI AEROSPHERE ${ }^{\circledR}$; TRIXEO AEROSPHERETM). Both drugs have been approved in the US, ${ }^{22,23}$ Europe, ${ }^{24,25} \operatorname{Japan}^{26,27}$ and China $^{28,29}$ for the treatment of COPD. Additional monoand dual therapies using this technology have been developed for use as blinded comparators in clinical trials, including glycopyrrolate (GP) MDI, formoterol fumarate (FF) MDI, and budesonide/formoterol fumarate (BFF) MDI. Phase III pivotal and extension studies of GFF MDI and
BGF MDI have demonstrated their clinical efficacy and tolerability in patients with moderate-to-very severe COPD, with benefits on lung function, symptoms, and exacerbations versus their corresponding monotherapies and dual therapies, respectively. ${ }^{30-34}$

\section{Attributes of Co-Suspension Delivery Technology Dose Consistency}

The consistency and reliability of GFF MDI and BGF MDI using co-suspension delivery technology have been investigated in vitro in various simulated patient-use

Table I Features of the Aerosphere Inhaler Formulated Using Co-Suspension Delivery Technology

\begin{tabular}{|l|l|}
\hline Technical Attribute & Potential Benefits in Practice \\
\hline $\begin{array}{l}\text { Comparable fine particle fraction, MMAD, and particle size } \\
\text { distribution of all components in the inhaler }{ }^{20}\end{array}$ & $\begin{array}{l}\text { Components in combination inhalers are delivered to all regions of the lung } \\
\text { in a consistent ratio. }\end{array}$ \\
\hline $\begin{array}{l}\text { Comparable aerosol performance and lung deposition across } \\
\text { inspiratory flow rates } 35,40,44\end{array}$ & $\begin{array}{l}\text { Patients receive a consistent dose of medication even with daily variation in } \\
\text { their inspiratory flow rates. } \\
\text { Patients with a suboptimal inspiratory flow rate for MDI use will still receive } \\
\text { an adequate dose of medication. }\end{array}$ \\
\hline $\begin{array}{l}\text { Tolerant of device handling errors: } \\
\text { - Shaking technique } \\
\text { - Delay before actuation }\end{array}$ & $\begin{array}{l}\text { Patients receive a sufficient dose of medication despite suboptimal inhalation } \\
\text { technique or occasional errors in device use. }\end{array}$ \\
\hline $\begin{array}{l}\text { Optimal particle size enables delivery to the large and small } \\
\text { airways }\end{array}$ & \begin{tabular}{l} 
Treatment benefits are observed throughout the lung. \\
\hline
\end{tabular}
\end{tabular}

Abbreviations: MDI, metered dose inhaler; MMAD, mass median aerodynamic diameter. 
situations. ${ }^{35,36}$ In a study by Doty et al, ${ }^{35}$ the MMAD, FPF, and particle size distribution of GP and FF were shown to be consistent, whether formulated and delivered as monocomponents, or in the dual GFF MDI combination. ${ }^{35}$ The MMAD for both components ranged from 3.0 to $3.2,{ }^{35}$ within the optimal particle size range for effective drug delivery to both the central and peripheral airways. ${ }^{12}$ The FPFs for GP and FF, when delivered via GFF MDI, were high and comparable between components (59\% and 57\%, respectively), displaying a similar or greater FPF and degree of consistency versus some other dual combination therapies. ${ }^{18,35,37-39}$ The aerodynamic particle size distribution of BGF MDI in comparison to GFF MDI and BFF MDI has also been assessed. ${ }^{36}$ All three treatments displayed a similar fine particle mass $(<6.4 \mu \mathrm{m})$, indicating that the addition of a third active component did not alter dosing from the MDI.

Use of an incorrect flow rate when inhaling is a common error associated with the use of MDIs, which should ideally be administered with a slow, deep inhalation. ${ }^{4,5}$ The FPFs (defined as \% of particles $<5 \mu \mathrm{m}$ ) of both components in GFF MDI were $61 \%$ to $69 \%$ across simulated flow rates from $30 \mathrm{~L} / \mathrm{min}$ (slow inhalation) to $90 \mathrm{~L} / \mathrm{min}$ (rapid inhalation). ${ }^{35}$ Similar assessments of FPF according to flow rate have also been performed with BGF MDI. ${ }^{40}$ The FPFs of the three components in BGF MDI were $47 \%$ to $51 \%$ at a flow rate of $30 \mathrm{~L} / \mathrm{min}$ and $58 \%$ to $61 \%$ at $60 \mathrm{~L} / \mathrm{min}$. This consistency in FPF for the components of GFF MDI and BGF MDI may be beneficial for patients who experience daily variation in their peak inspiratory flow rates and volumes, although this has not been formally assessed.

Suspension MDI formulations must be shaken prior to administration, and this is a common source of error in MDI use. ${ }^{4} \mathrm{~A}$ delay between shaking and actuation with traditional drug crystal MDIs can lead to variability in the delivered dose due to creaming or settling of the suspension. ${ }^{41}$ Insufficient shaking of traditional MDIs can reduce systemic availability by almost one half. ${ }^{42}$ To assess the impact of the Aerosphere inhaler and cosuspension delivery technology on dose consistency, the delivered doses from GFF MDI and BGF MDI were compared with different shaking techniques and delays. $^{35,36}$ Regardless of whether a single inversion, a standard shake, or a gentle shake was used, both GFF MDI and BGF MDI delivered doses within the target range, suggesting that co-suspension delivery technology MDIs have similar performance to solution
Glycopyrrolate Formoterol fumarate Budesonide

A

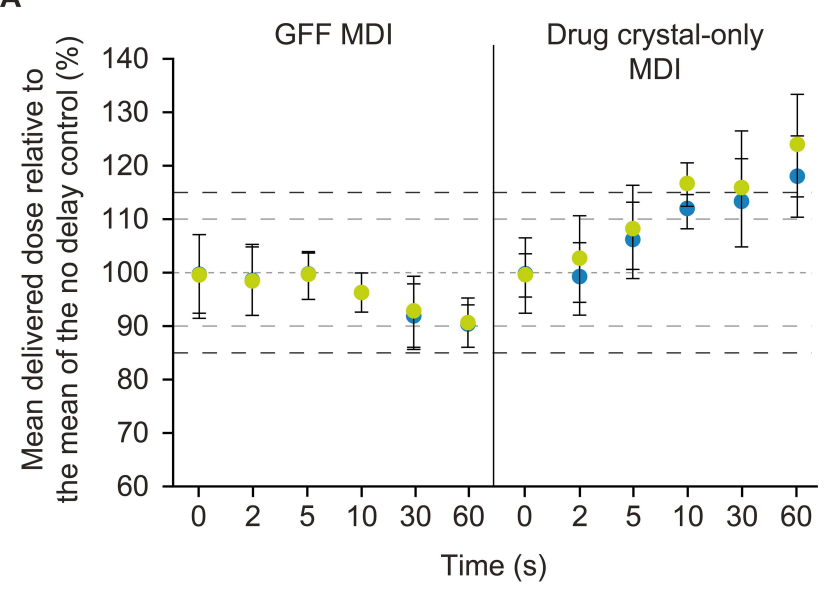

B

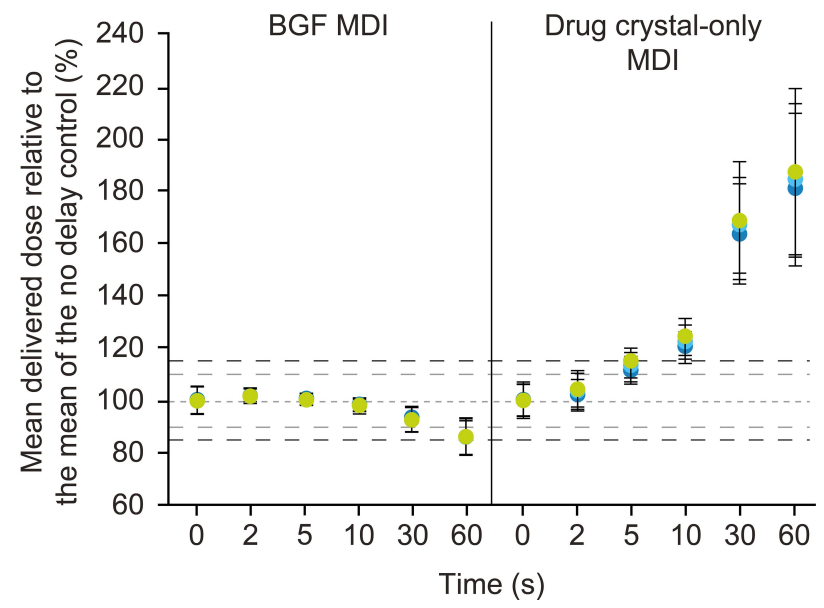

Figure 2 Effect of delay from shaking to actuation on dose consistency of: (A) GFF MDI and (B) BGF MDI compared to drug crystal-only MDls. Panel A adapted from Doty et al (CC BY). ${ }^{35}$ Panel B adapted from Sheth et al. ${ }^{36}$ Error bars represent \pm 1 SD. Reference lines presented at $85 \%, 90 \%, 100 \%, 110 \%$ and I I $5 \%$. For each, $N=10$ delivered doses were collected per product and delay time.

Abbreviations: BGF, budesonide/glycopyrrolate/formoterol fumarate; GFF, glycopyrrolate/formoterol fumarate; MDI, metered dose inhaler; SD, standard deviation.

MDIs in delivering a reliable dose across a range of shake energies. In addition, GFF MDI and BGF MDI delivered consistent doses (within 15\%) regardless of delays up to 60 seconds between shaking and actuation (Figure 2A and B), showing that co-suspension delivery technology MDIs are minimally affected by delays between shaking and use. Overall, these findings provide evidence of reliable drug delivery from MDIs formulated using co-suspension delivery technology, with dose consistency observed across the lifetime of the inhaler and in several simulated patient handling conditions. 


\section{Lung Deposition Studies}

The lung deposition of inhaled therapies can be assessed via several imaging techniques, including in vivo methods (eg gamma scintigraphy ${ }^{43}$ ) as well as newer in silico modeling techniques (using a computer simulation, eg functional respiratory imaging $[\mathrm{FRI}]^{11}$ ). The first assessments of the lung deposition of MDIs formulated using cosuspension delivery technology were performed in silico using FRI (further details regarding the method can be found in Supplementary file 1$) \cdot{ }^{44}$ FRI is a postprocessing technology that applies computational fluid dynamics to high-resolution computed tomography (CT) scans of the lungs. ${ }^{45}$ It can be used to assess both drug deposition and airway geometry (further described in the section below), and was used to develop computational flow simulations based on CT scans obtained from patients with mild-to-very severe COPD. The total lung deposition of mono (GP MDI and FF MDI), dual (GFF MDI) and triple (BGF MDI) combinations delivered using a single Aerosphere inhaler device remained consistent regardless of the number of components in the formulation.

A similar in silico study was performed to compare the lung deposition of BGF MDI with fluticasone furoate/umeclidinium/vilanterol (FLU/UMEC/VI), a DPI formulation. ${ }^{40}$ Lung deposition of the three components in BGF MDI ranged from $40 \%$ to $48 \%$ at simulated mean inhalation flow rates of $30 \mathrm{~L} / \mathrm{min}$ and $60 \mathrm{~L} / \mathrm{min}$, while FLU/UMEC/ VI showed $14 \%$ to $27 \%$ deposition (at simulated mean inhalation flow rates of $29 \mathrm{~L} / \mathrm{min}$ and $69 \mathrm{~L} / \mathrm{min}$ ). In this comparison, BGF MDI showed a higher total lung deposition fraction and lower variability across drug components than the DPI formulation. The simulation also estimated central/peripheral $(\mathrm{C} / \mathrm{P})$ ratios of 1.1 to 1.7 for $\mathrm{BGF}$ MDI across flow rates, which would suggest delivery in both the proximal and distal airways in vivo. ${ }^{46}$

The in vivo lung deposition of GFF MDI and BGF MDI has been assessed in healthy adults using gamma scintigraphy ${ }^{46,47}$ This technique uses radiolabeling to quantify regional drug deposition in the lung, and can also assess the amount of drug deposited in the extrathoracic region. ${ }^{48-50}$ Following administration of a single dose with a standard 10-second breath-hold, the percentage of the emitted dose deposited in the lungs was $38.4 \%$ with GFF MDI and $37.7 \%$ with BGF MDI. ${ }^{46,47}$ This fraction is similar to, or higher than, that observed in previous gamma scintigraphy studies of other suspension MDIs in healthy subjects and patients with COPD or asthma. ${ }^{46,51-54}$ For both drugs, a very low fraction of the dose $(<0.3 \%)$ was exhaled and the remainder (61\% to $62 \%)$ was deposited in the oropharyngeal or stomach regions. ${ }^{46,47}$ Regional deposition results indicated that GFF MDI and BGF MDI were delivered to both the central and peripheral lung regions. The normalized outer/inner (nO/I, also known as the penetration index [PI]) and standardized $\mathrm{C} / \mathrm{P}(\mathrm{sC} / \mathrm{P})$ deposition ratios were 0.57 and 1.85 , respectively, for GFF MDI, and 0.65 and 1.79, respectively, for BGF MDI. These ratios indicated a comparable or slightly larger proportion of drug deposited in the distal airways compared to previous lung deposition studies of suspension MDIs in COPD and asthma. ${ }^{51,52,55}$

The gamma scintigraphy study of BGF MDI also assessed the effect of breath-hold duration on lung deposition. Notably, the lung deposition of BGF MDI was 34.9\% with a 3 -second breath-hold and $40.3 \%$ with a 10 -second breath-hold (difference of 5.5\%), and peripheral deposition (as measured by $\mathrm{nO} / \mathrm{I}$ and $\mathrm{sC} / \mathrm{P}$ ratios) was not adversely affected by the shorter breath-hold. ${ }^{47}$ Overall, these data indicate that combination therapies delivered via a single Aerosphere inhaler using co-suspension delivery technology show improved lung deposition versus traditional MDI formulations, with drug delivery throughout the whole lung, even with a breath-hold of only 3 seconds.

\section{Functional Respiratory Imaging Studies of Airway Geometry}

In addition to lung deposition modeling (described above), FRI can also be used to characterize airway geometry with regional specificity. ${ }^{45}$ Previous studies using FRI have assessed the effects of respiratory medications on imagebased parameters including airway volume and resistance. $^{56-60}$ These outcomes are highly correlated with traditional lung function assessments, ${ }^{56}$ but have increased sensitivity to detect treatment effects in small numbers of patients. ${ }^{61}$

Two FRI studies of MDIs formulated using co-suspension delivery technology have been conducted in patients with moderate-to-severe COPD. ${ }^{56,61}$ The first of these studies compared GFF MDI with placebo MDI ${ }^{56}$ whereas the second evaluated the monocomponents of GFF MDI: GP MDI and FF MDI. ${ }^{61}$ Both studies used a crossover design with two 14day treatment periods, separated by a washout period of 5 to 21 days. The co-primary FRI endpoints in both studies were the specific (ie adjusted for lobar volume) image-based airway volume and resistance (siVaw and siRaw) after 14 days of treatment. Traditional lung function endpoints (including 
- GFF MDI - Placebo MDI

GP MDI $\because \mathrm{FF} \mathrm{MDI}$

A
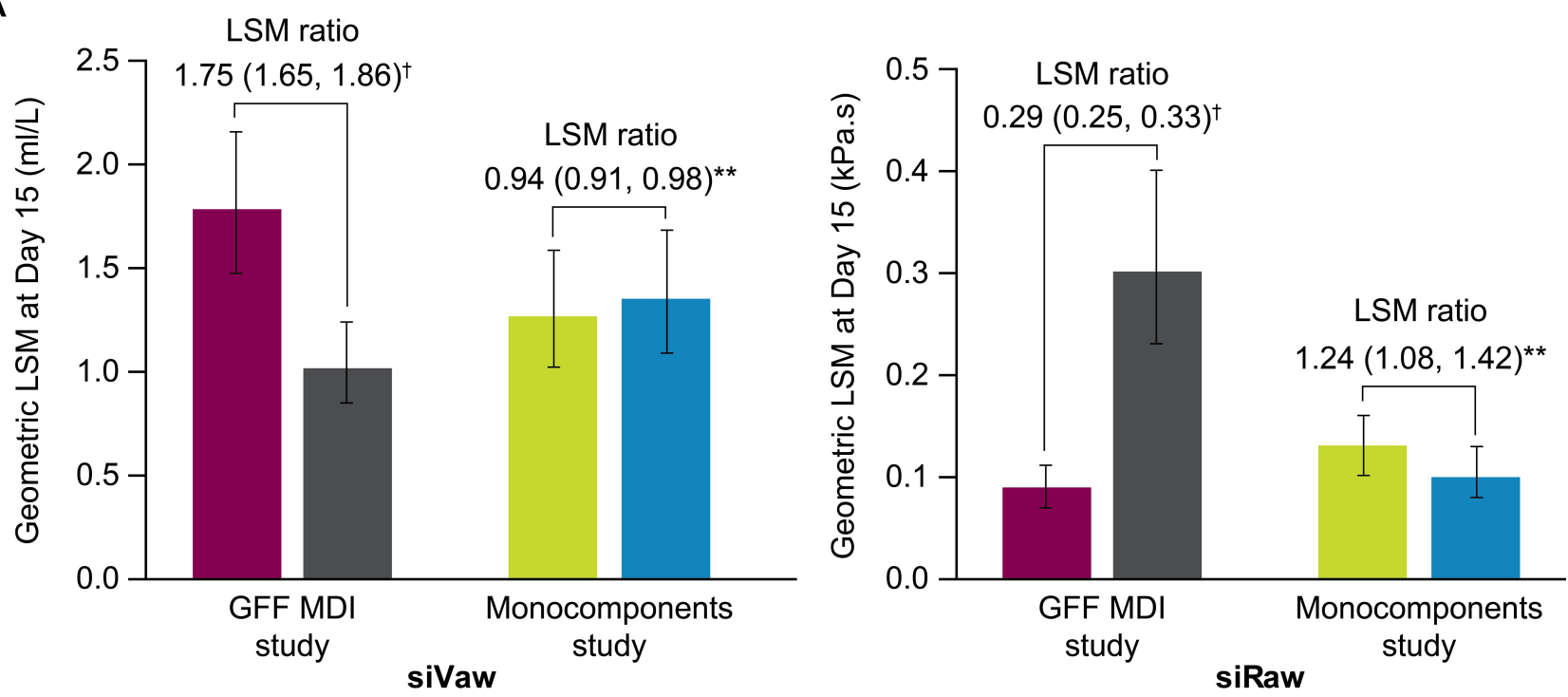

B

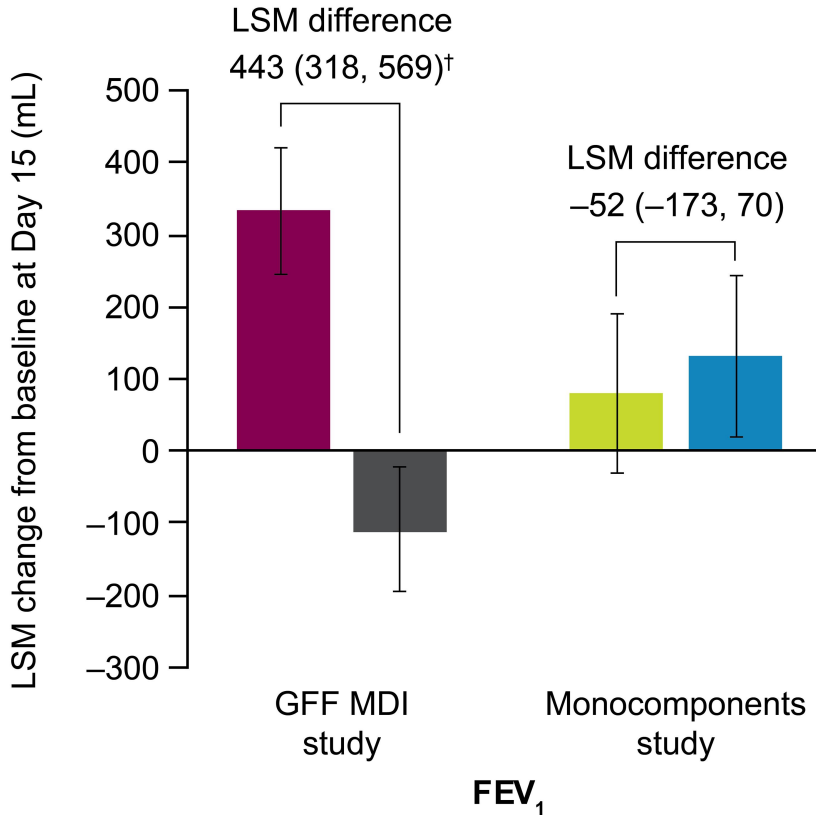

LSM difference $454(209,699)^{\star * *}$
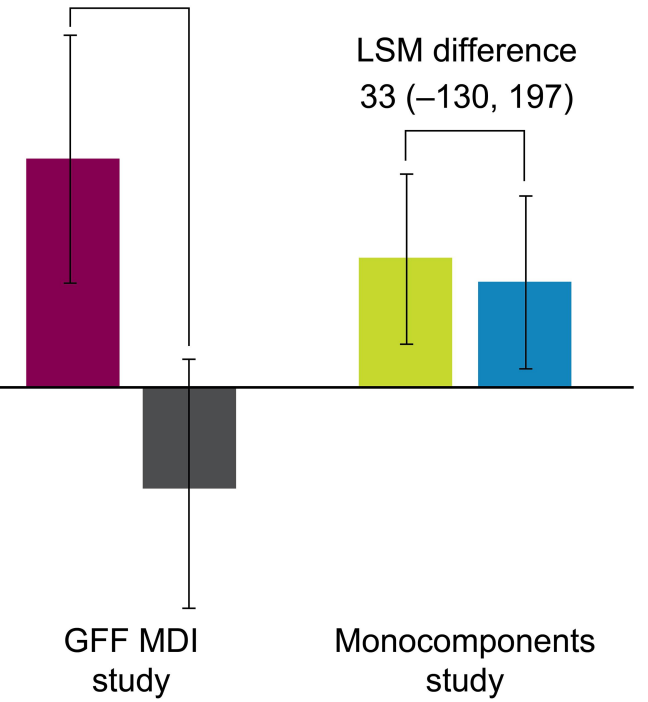

IC

Figure 3 Results from two FRI studies using co-suspension delivery technology MDIs ${ }^{54,59}$ : (A) FRI endpoints and (B) spirometry endpoints.

Notes: $\mathrm{N}=19$ in all analyses except IC for FF MDI $(\mathrm{N}=18)$. Horizontal bars between treatments are labelled with $\mathrm{LSM}$ ratio $(95 \% \mathrm{Cl})$ in $(\mathrm{A})$, and $\mathrm{LSM}$ difference $(95 \% \mathrm{Cl})$ in (B). Error bars represent $95 \% \mathrm{Cl}$. ${ }^{* *} \mathrm{p}<0.01$, ${ }^{* * *} \mathrm{p}<0.00 \mathrm{I},{ }^{\dagger} \mathrm{p}<0.000 \mathrm{I}$.

Abbreviations: $\mathrm{Cl}$, confidence interval; $\mathrm{FEV}_{1}$, forced expiratory volume in I s; FF, formoterol fumarate; FRI, functional respiratory imaging; GFF, glycopyrrolate/formoterol fumarate; GP, glycopyrrolate; IC, inspiratory capacity; LSM, least squares mean; MDI, metered dose inhaler; siRaw, specific image-based airway resistance; siVaw, specific image-based airway volume.

forced expiratory volume in $1 \mathrm{~s}\left[\mathrm{FEV}_{1}\right]$ and inspiratory capacity [IC]) were also assessed using spirometry. Efficacy assessments were conducted between 60 and 150 minutes postdosing.

The results for key endpoints from these studies are shown in Figure 3. In the GFF MDI study, there were large improvements in siVaw (75\% increase) and siRaw (71\% decrease) versus placebo MDI at Day 15 with the effects observed across all lobes of the lung (Figure 3A, $4 \mathrm{~A}$ and B). ${ }^{56}$ These changes were accompanied by clinically meaningful improvements in spirometry and body plethysmography endpoints, with differences for GFF 
MDI versus placebo of $443 \mathrm{~mL}$ and $454 \mathrm{~mL}$ for $\mathrm{FEV}_{1}$ and IC (Figure 3B), and $13 \%$ and $22 \%$ reductions versus placebo for functional residual capacity and residual volume. At the patient level, improvements in FRI parameters were strongly correlated with the change from baseline in $\mathrm{FEV}_{1}$, supporting the validity of this imagebased technique to assess bronchodilator medications in respiratory disease, with the added benefit of providing information regarding the regional distribution of the observed effects.

In the monocomponents study, both GP MDI and FF MDI significantly improved siVaw and siRaw compared to baseline, with most patients showing improvement after 14 days with both treatments. ${ }^{61}$ Overall, larger improvements in FRI endpoints and $\mathrm{FEV}_{1}$ were seen with FF MDI compared to GP MDI (Figure 3A and B), potentially reflecting the timing of the post-dose assessments and the faster onset of action of formoterol. However, there were some individual patients who experienced greater improvements in airway volume and resistance with GP MDI compared with FF MDI, and the average improvement in IC was slightly larger for GP MDI compared with FF MDI (Figure 3B). The FRI endpoints were more sensitive relative to traditional lung function endpoints in detecting treatment differences in a small number of patients, as statistically significant differences between GP MDI and FF MDI were observed with FRI but not with spirometry and body plethysmography. Image-based airway volume (iVaw; not adjusted for lobar volume) was also assessed at each airway generation. These analyses showed that both GP MDI and FF MDI acted across airway generations, with an interaction between treatment and generation such that the magnitude of difference between GP MDI and FF MDI varied across generations in absolute terms, although the general relative pattern across airway generations was similar between treatments.

These two studies did not include a common comparator and therefore the findings cannot be directly compared. However, when taken together, the results of both studies suggest that GFF MDI provides larger improvements in both FRI and spirometry outcomes compared with its monocomponents GP MDI and FF MDI (Figure 4). Geometric least squares means for siVaw at Day 15 were 1.79 for GFF MDI versus 1.02 for placebo, and 1.27 for GP MDI versus 1.35 for FF MDI. For siRaw at Day 15, the geometric least squares means were 0.09 for GFF MDI versus 0.30 for placebo MDI, and 0.13 for GP MDI versus 0.10 for FF MDI. Both studies were conducted in Belgium and the patient populations were generally similar between the two studies, although the monocomponents study enrolled more patients with severe COPD (30\% vs $15 \%)$. Overall, the findings of these FRI studies generally demonstrated the clinically meaningful benefits of GFF MDI on airway volume and resistance in comparison with placebo, and suggest greater benefits with dual bronchodilator therapy compared with LAMA or LABA monotherapy.

\section{Discussion and Conclusions}

The co-suspension delivery technology used in the Aerosphere inhaler has overcome many of the traditional challenges in MDI formulation and allowed for the development of combination therapies for COPD with improved stability and homogeneity compared with traditional suspension formulations. ${ }^{18,20}$ This formulation technology uses innovative, aerodynamic porous particles composed of phospholipids, an endogenous component of lung surfactant, to allow dispersion and deposition of drug crystals on the airway surface. Furthermore, this technology delivers a consistent dose with an optimal particle size distribution for whole lung distribution, regardless of whether one, two, or three drugs are delivered from the inhaler, ${ }^{12,18,20,35,36}$ and display a similar or higher FPF compared to other combination therapies. ${ }^{18,35,37-39}$ Currently, two FDCs, each delivered using a single Aerosphere inhaler, have been developed (GFF MDI and BGF MDI). These therapies combine two bronchodilators with complementary modes of action (ie a LAMA and a LABA) in a single inhaler, with BGF MDI also containing an ICS component, providing patients with the option to step up from a LAMA/LABA to an ICS/LAMA/LABA using the same device.

In prescribing an inhaler device, it is important for clinicians to consider patient preference, ability, and disease characteristics. ${ }^{1,62}$ Many patients with COPD are familiar with the use of an MDI as most short-acting rescue medications are provided in this device type. The availability of MDI formulations for dual and triple combination therapies allows patients to maintain the same device type across their rescue and maintenance medications. Studies have shown that for patients with COPD or asthma using multiple inhalers, use of the same or similar device type can improve clinical outcomes. ${ }^{63,64}$ Some patients may have difficulty with the hand-breath coordination required to use an MDI correctly; however, MDIs can be used with a spacer device, which can improve drug delivery in these patients. ${ }^{65}$ The use of an MDI is also recommended for those who have 
A
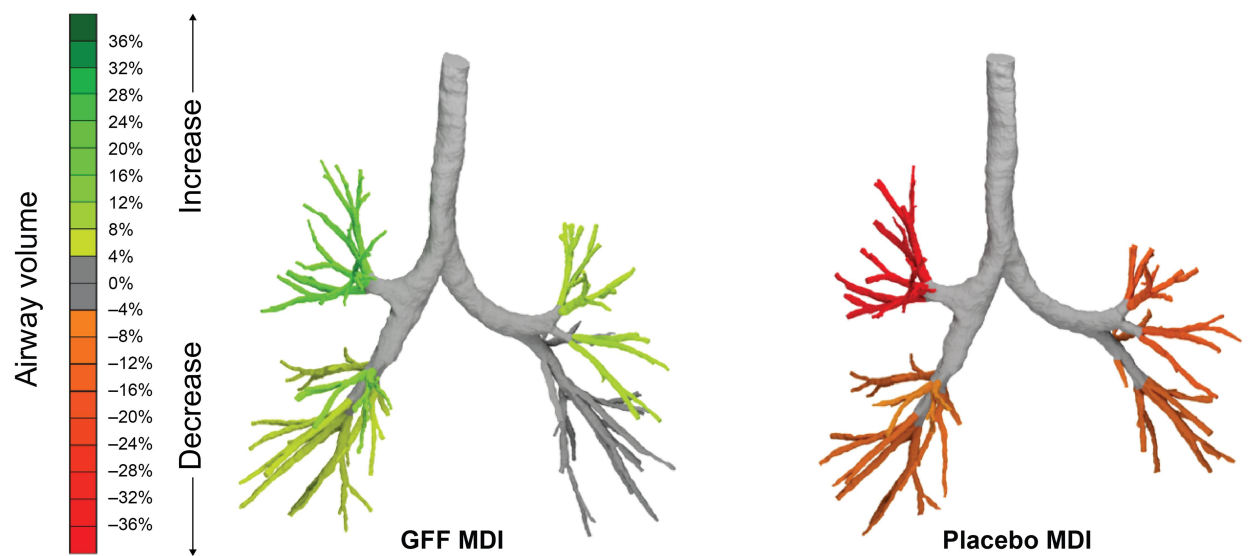

B
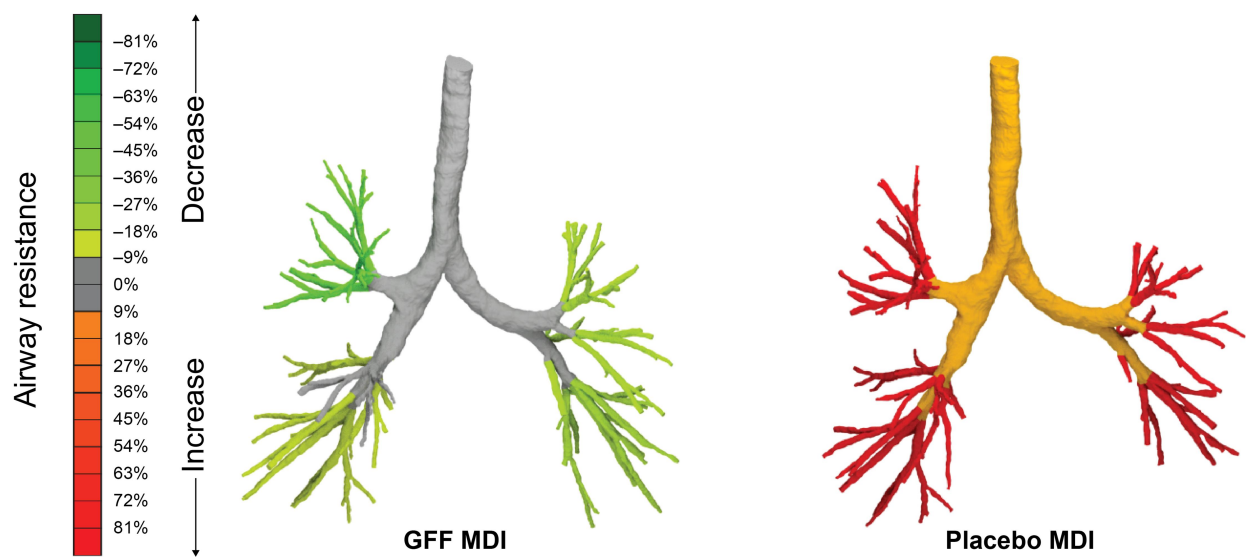

Figure 4 Changes in specific image-based: (A) airway volume and (B) airway resistance at Day 15, after treatment with GFF MDI or placebo MDI. Adapted from International Journal of COPD 2018:13 2673-2684 - Originally published by and used with permission from Dove Medical Press Limited. ${ }^{56}$ Images from one representative patient.

Abbreviations: GFF, glycopyrrolate/formoterol fumarate; MDI, metered dose inhaler.

insufficient inspiratory flow to use DPIs, ${ }^{66}$ which is observed in some elderly patients. ${ }^{67}$ Suspension MDIs require shaking before actuation and a slow, deep inhalation during drug delivery, and it is common for patients to perform these steps incorrectly. ${ }^{4}$ Therefore, it is notable that the Aerosphere inhaler, formulated using co-suspension delivery technology, displays consistent dose delivery across a variety of inspiratory flow rates and shaking techniques, ${ }^{35,36,40,44}$ potentially mitigating the impact of these common MDI handling errors. This consistency also helps ensure that patients receive a full dose throughout the lifetime of their inhaler, as the compounding effects of variable dose delivery could result in patients running out of drug before the end of the labeled period.

Co-suspension delivery technology MDIs provide efficient drug delivery throughout the proximal and distal airways, with consistent deposition of all drug components in the inhaler. ${ }^{40,44,46,47}$ Compared to traditional MDI formulations, GFF MDI and BGF MDI display similar or higher total lung deposition, as well as C/P airway deposition, as shown by gamma scintigraphy data in healthy adults. ${ }^{46,47}$ In silico evidence from a lung deposition simulation using FRI found that all three components of BGF MDI were deposited in the lung at similarly high rates, while a triple therapy comparator delivered via a DPI (FLU/UMEC/VI) showed lower deposition overall, particularly of the ICS component. ${ }^{40}$ Although this remains to be formally demonstrated, the more uniform deposition of co-suspension delivery technology MDIs compared to other inhaler formulations may translate into clinical benefits for patients, as inhaled therapies must reach the inner and outer regions of the lung, as well as both the central 
and peripheral airways to provide effective bronchodilation. $^{48}$ Furthermore, co-suspension delivery technology supports co-localization of combination inhaler components, as the drugs are suspended with porous phospholipid particles. ${ }^{18,20}$ This may potentially enhance the complementary action of different drug classes, which is supported by data showing synergism between ICS and LABA in patients with COPD. ${ }^{68}$ The lung deposition of BGF MDI was also shown to be minimally affected by breath-hold duration. ${ }^{47}$ When administering an MDI, patients are advised to hold their breath for at least 5 to 10 seconds. ${ }^{69}$ However, studies of patient handling errors have found that approximately half of MDI users failed to demonstrate an appropriate breath-hold following inhalation. $^{4,5}$ In addition, patients with COPD, especially those with severe disease, may be unable to maintain a breath-hold for this length of time. Therefore, the consistent lung deposition of BGF MDI may benefit patients who have suboptimal breath-hold times, either due to inhaler technique or disease characteristics. An in vivo gamma scintigraphy study of BGF MDI in COPD and a similar study using FRI have recently been completed. $^{70,71}$ Given that spacers are an important part of inhaler management, ${ }^{72}$ it would also be interesting to consider future FRI studies assessing the deposition of BGF MDI with and without a spacer.

An FRI study of GFF MDI has also shown clinically meaningful improvements in airway volume and resistance throughout all lobes of the lung after 2 weeks' treatment in patients with COPD. ${ }^{56}$ As expected, these improvements in airway volume and resistance in the central and peripheral lung were associated with a clinically meaningful increase in airflow $\left(\mathrm{FEV}_{1} 443 \mathrm{~mL}\right.$ vs placebo) and reduced lung hyperinflation (IC $454 \mathrm{~mL}$ vs placebo). ${ }^{56}$ An FRI study of the monocomponents of GFF MDI (GP MDI and FF MDI) found that some patients with COPD respond better to either the LAMA component or the LABA component. ${ }^{61}$ This finding suggests that the risk of an inadequate response may be lower when initiating treatment with a dual bronchodilator than with monotherapy.

The versatility of the co-suspension delivery technology used in the Aerosphere inhaler allows for the development of additional combination treatments for COPD and other respiratory conditions. An FDC of budesonide/ albuterol formulated using co-suspension delivery technology is currently in Phase III clinical development for asthma. $^{73,74}$
In conclusion, patient treatment needs vary based on their preferences, abilities, and disease characteristics, and thus the availability of inhaled therapies in MDI formulations remains an important option for personalization of COPD therapy. Studies thus far suggest that the Aerosphere inhaler, formulated using cosuspension delivery technology, may offer advantages over traditional MDIs, including consistent delivery of multiple components across patient handling conditions, optimal particle size and FPF, and effective delivery to the central and peripheral airways. Future studies may provide additional evidence regarding the clinical benefits of these technical improvements in MDI drug delivery.

\section{Abbreviations}

$\mathrm{BD}$, budesonide; BFF, budesonide/formoterol fumarate; BGF, budesonide/glycopyrrolate/formoterol fumarate; $\mathrm{CaCl}_{2}$, calcium chloride; CFCs, chlorofluorocarbons; $\mathrm{CI}$, confidence interval; COPD, chronic obstructive pulmonary disease; C/P, central/peripheral; DPI, dry powder inhaler; DT, delivery technology; FDC, fixeddose combination; $\mathrm{FEV}_{1}$, forced expiratory volume in 1 s; FF, formoterol fumarate; FLU, fluticasone furoate; FPF, fine particle fractions; FRI, functional respiratory imaging; GFF, glycopyrrolate/formoterol fumarate; GP, glycopyrrolate; HFAs, hydrofluoroalkanes; IC, inspiratory capacity; ICS, inhaled corticosteroids; iVaw, image-based airway volume; LABA, long-acting $\beta_{2-}$ agonist; LAMA, long-acting muscarinic antagonist; LSM, least squares mean; MDI, metered dose inhaler; MMAD, mass median aerodynamic diameter; $\mathrm{nO} / \mathrm{I}$, normalized outer inner; PI, penetration index; pMDI, pressurized metered dose inhaler; $\mathrm{sC} / \mathrm{P}$, standardized central/peripheral; siRaw, specific image-based airway resistance; siVaw, specific image-based airway volume; SMI, soft mist inhaler; UMEC, umeclidinium; VI, vilanterol.

\section{Data Sharing Statement}

Data underlying the findings described in this manuscript may be obtained in accordance with AstraZeneca's data sharing policy described at https://astrazenecagrouptrials. pharmacm.com/ST/Submission/Disclosure.

\section{Consent for Publication}

All authors provide consent for publication. 


\section{Acknowledgment}

The Aerosphere inhaler studies discussed in this review were supported by AstraZeneca. The authors thank all the patients and their families and the team of investigators involved in the studies. The authors also thank FLUIDDA for their valuable contributions to the FRI and in silico studies. Medical writing support, under the direction of the authors, was provided by Julia King, $\mathrm{PhD}$, CMC Connect, McCann Health Medical Communications, which was funded by AstraZeneca in accordance with Good Publication Practice (GPP3) guidelines. $^{75}$

\section{Author Contributions}

All authors contributed to data analysis, drafting or revising the article, have agreed on the journal to which the article will be submitted, gave final approval of the version to be published, and agree to be accountable for all aspects of the work.

\section{Funding}

This review was supported by AstraZeneca.

\section{Disclosure}

OSU has received industry-academic funding from AstraZeneca, Boehringer Ingelheim, Chiesi, Edmond Pharma, GlaxoSmithKline, and Mundipharma International, and has received consultancy or speaker fees from AstraZeneca, Boehringer Ingelheim, Chiesi, Cipla, Covis, Edmond Pharma, GlaxoSmithKline, Menarini, Mereo BioPharma, Mundipharma International, Napp, Novartis, Orion, Roche, Sandoz, Takeda, and UCB. NR reports grants and personal fees from Boehringer Ingelheim, Novartis, and Pfizer, personal fees from $3 \mathrm{M}$, AstraZeneca, Chiesi, Cipla, GlaxoSmithKline, Mundipharma, Sandoz, Sanofi, Teva, Trudell, and Zambon, outside the submitted work. MJ, NS, and PM are employees of AstraZeneca. WDB has no real or perceived conflicts of interest that relate to this manuscript. His department has received grants from AstraZeneca, Chiesi, and GlaxoSmithKline.

\section{References}

1. Global Initiative for Chronic Obstructive Lung Disease. 2020 report: global strategy for the diagnosis, management and prevention of COPD. 2020. Available from: https://goldcopd.org/gold-reports/. Accessed March 17, 2020.
2. Global Initiative for Asthma. 2019 Report: global strategy for asthma management and prevention. 2019. Available from: https://ginasthma. org/. Accessed December 17, 2019.

3. Usmani OS. Choosing the right inhaler for your asthma or COPD patient. Ther Clin Risk Manag. 2019;15(14):461-472. doi:10.2147/ TCRM.S160365

4. Melani AS, Bonavia M, Cilenti V, et al. Inhaler mishandling remains common in real life and is associated with reduced disease control. Respir Med. 2011;105(6):930-938. doi:10.1016/j. rmed.2011.01.005

5. Sanchis J, Gich I, Pedersen S. Systematic review of errors in inhaler use: has patient technique improved over time? Chest. 2016;150 (2):394-406. doi:10.1016/j.chest.2016.03.041

6. Lavorini F, Usmani OS. Correct inhalation technique is critical in achieving good asthma control. Prim Care Respir J. 2013;22 (4):385-386. doi:10.4104/pcrj.2013.00097

7. Usmani OS, Lavorini F, Marshall J, et al. Critical inhaler errors in asthma and COPD: a systematic review of impact on health outcomes. Respir Res. 2018;19(1):10. doi:10.1186/s12931-0170710-y

8. Chrystyn H, van der Palen J, Sharma R, et al. Device errors in asthma and COPD: systematic literature review and meta-analysis. NPJ Prim Care Respir Med. 2017;27(1):22. doi:10.1038/s41533-017-0016-Z

9. Giraud V, Roche N. Misuse of corticosteroid metered-dose inhaler is associated with decreased asthma stability. Eur Respir J. 2002;19 (2):246-251. doi:10.1183/09031936.02.00218402

10. Usmani OS, Biddiscombe MF, Barnes PJ. Regional lung deposition and bronchodilator response as a function of $\beta_{2}$-agonist particle size. Am J Respir Crit Care Med. 2005;172(12):1497-1504. doi:10.1164/ rccm.200410-1414OC

11. Van Holsbeke C, De Backer J, Vos W, Marshall J. Use of functional respiratory imaging to characterize the effect of inhalation profile and particle size on lung deposition of inhaled corticosteroid/long-acting $\beta_{2}$-agonists delivered via a pressurized metered-dose inhaler. Ther Adv Respir Dis. 2018;12:1753466618760948. doi:10.1177/17534666 18760948

12. Darquenne C. Aerosol deposition in health and disease. $J$ Aerosol Med Pulm Drug Deliv. 2012;25(3):140-147. doi:10.1089/jamp. 2011.0916

13. Verbanck S, Biddiscombe MF, Usmani OS. Inhaled aerosol dose distribution between proximal bronchi and lung periphery. Eur J Pharm Biopharmaceutics. 2020;152:18-22. doi:10.1016/j.ejpb.20 20.04.019

14. Ding B, Kallenbach L, Slipski L, Wilk A, O'Brien D, Guranlioglu D. Demographics and clinical characteristics of patients with COPD utilizing LAMA/LABA fixed-dose combination therapy: a U.S. database study. Thorax. 2018;73(Suppl 4):A233-A233. doi:10.1136/thorax-2018-212555.399

15. Stein SW, Sheth P, Hodson PD, Myrdal PB. Advances in metered dose inhaler technology: hardware development. AAPS PharmSciTech. 2014;15(2):326-338. doi:10.1208/s12249-013-0062-y

16. Newman SP. Principles of metered-dose inhaler design. Respir Care. 2005;50(9):1177-1190.

17. Myrdal PB, Sheth P, Stein SW. Advances in metered dose inhaler technology: formulation development. AAPS PharmSciTech. 2014;15 (2):434-455. doi:10.1208/s12249-013-0063-x

18. Lechuga-Ballesteros D, Noga B, Vehring R, Cummings RH, Dwivedi SK. Novel cosuspension metered-dose inhalers for the combination therapy of chronic obstructive pulmonary disease and asthma. Future Med Chem. 2011;3(13):1703-1718. doi:10.4155/ fmc. 11.133

19. Michael Y, Snowden MJ, Chowdhry BZ, Ashurst IC, Davies-Cutting CJ, Riley T. Characterisation of the aggregation behaviour in a salmeterol and fluticasone propionate inhalation aerosol system. Int J Pharm. 2001;19(221(1-2)):165-174. doi:10.1016/S0378-5173 (01)00678-0 
20. Vehring R, Lechuga-Ballesteros D, Joshi V, Noga B, Dwivedi SK Cosuspensions of microcrystals and engineered microparticles for uniform and efficient delivery of respiratory therapeutics from pressurized metered dose inhalers. Langmuir. 2012;28(42):15015-15023. doi:10.1021/la302281n

21. Wauthoz N, Amighi K. Phospholipids in pulmonary drug delivery. Eur J Lipid Sci Technol. 2014;116(9):1114-1128. doi:10.1002/ejlt.20 1300368

22. AstraZeneca Pharmaceuticals LP. Bevespi Aerosphere ${ }^{\mathrm{TM}}$ Prescribing Information. 2019. Available from: http://www.azpicentral.com/beve spi/bevespi_pi.pdf. Accessed July 2, 2019.

23. AstraZeneca Pharmaceuticals LP. Breztri Aerosphere ${ }^{\mathrm{TM}}$ Prescribing Information. 2020. Available from: https://www.azpicentral.com/brez tri/breztri.pdf. Accessed November 13, 2020.

24. AstraZeneca AB. Bevespi Aerosphere summary of product characteristics. 2018. Available from: https://www.ema.europa.eu/ en/documents/product-information/bevespi-aerosphere-epar-productinformation_en.pdf. Accessed June 13, 2019.

25. European Medicines Agency. CHMP summary of positive opinion for Trixeo Aerosphere. 2020. Available from: https://www.ema. europa.eu/en/documents/smop-initial/chmp-summary-positiveopinion-trixeo-aerosphere_en.pdf. Accessed November 13, 2020

26. AstraZeneca. Bevespi Aerosphere approved by the Japanese Ministry of Health, Labour and Welfare for patients with chronic obstructive pulmonary disease. 2019. Available from: https://www.astrazeneca. com/media-centre/press-releases/2019/bevespi-aerosphere-approvedby-the-japanese-ministry-of-health-labour-and-welfare-for-patientswith-chronic-obstructive-pulmonary-disease-19062019.html. Accessed 2 July 2019.

27. AstraZeneca. Breztri Aerosphere (PT010) approved in Japan for patients with chronic obstructive pulmonary disease. 2019. Available from: https://www.astrazeneca.com/media-centre/pressreleases/2019/breztri-aerosphere-pt010-approved-in-japan-forpatients-with-chronic-obstructive-pulmonary-disease-19062019.html. Accessed July 2, 2019.

28. AstraZeneca. Bevespi Aerosphere approved in China for patients with COPD. 2020. Available from: https://www.astrazeneca.com/ media-centre/press-releases/2020/bevespi-aerosphere-approved-inchina-for-patients-with-copd.html. Accessed July 7, 2020.

29. AstraZeneca. AstraZeneca's triple-combination therapy approved in China for patients with COPD. 2019. Available from: https://www. astrazeneca.com/media-centre/press-releases/2019/astrazenecas-triple -combination-therapy-approved-in-china-for-patients-with-copd -23122019.html. Accessed December 23, 2019.

30. Martinez FJ, Rabe KF, Ferguson GT, et al. Efficacy and safety of glycopyrrolate/formoterol metered dose inhaler formulated using co-suspension delivery technology in patients with COPD. Chest. 2017;151(2):340-357. doi:10.1016/j.chest.2016.11.028

31. Lipworth BJ, Collier DJ, Gon Y, et al. Improved lung function and patient-reported outcomes with co-suspension delivery technology glycopyrrolate/formoterol fumarate metered dose inhaler in COPD: a randomized phase III study conducted in Asia, Europe, and the USA. Int J Chron Obstruct Pulmon Dis. 2018;13:2969-2984. doi:10.2147/COPD.S171835

32. Hanania NA, Tashkin DP, Kerwin EM, et al. Long-term safety and efficacy of glycopyrrolate/formoterol metered dose inhaler using novel Co-Suspension ${ }^{\mathrm{TM}}$ Delivery Technology in patients with chronic obstructive pulmonary disease. Respir Med. 2017;126:105-115. doi:10.1016/j.rmed.2017.03.015

33. Ferguson GT, Rabe KF, Martinez FJ, et al. Triple therapy with budesonide/ glycopyrrolate/formoterol fumarate with co-suspension delivery technology versus dual therapies in chronic obstructive pulmonary disease (KRONOS): a double-blind, parallel-group, multicentre, Phase 3 randomised controlled trial. Lancet Respir Med. 2018;6(10):747-758. doi:10.1016/S2213-2600(18)30327-8
34. Martinez FJ, Fabbri LM, Ferguson GT, et al. Baseline symptom score impact on benefits of glycopyrrolate/formoterol metered dose inhaler in COPD. Chest. 2017;152(6):1169-1178. doi:10.1016/j.chest.2017.07.007

35. Doty A, Schroeder J, Vang K, et al. Drug delivery from an innovative LAMA/LABA co-suspension delivery technology fixed-dose combination MDI: evidence of consistency, robustness, and reliability. AAPS PharmSciTech. 2018;19(2):837-844. doi:10.1208/s12249-017-0891-1

36. Sheth P, Archbell J, Miller K, Wu L, Vang K, Mack P. Drug delivery from a novel fixed-dose ICS/LAMA/LABA MDI using co-suspension delivery technology: evidence of consistency, robustness, and reliability. Poster presented at: American Association of Pharmaceutical Scientists Pharmsci 360; 4 November 2019; San Antonio, Texas, USA. Available from: https://shwca.se/pharmsci2019. Accessed January 7, 2021.

37. Hamilton M, Leggett R, Pang C, Charles S, Gillett B, Prime D. In vitro dosing performance of the ELLIPTA ${ }^{\circledR}$ dry powder inhaler using asthma and COPD patient inhalation profiles replicated with the electronic lung (eLung). J Aerosol Med Pulm Drug Deliv. 2015;28 (6):498-506. doi:10.1089/jamp.2015.1225

38. De Maria R, Zagnoni I, Bodria A, et al. Foster ${ }^{\circledR}$ : a high-efficiency combination metered dose inhaler with consistent particle size distribution at alternative flow rates. Combination Prod Ther. 2014;4 (1):1-5. doi:10.1007/s13556-013-0006-6

39. Johal B, Howald M, Fischer M, Marshall J, Venthoye G. Fine particle profile of fluticasone propionate/formoterol fumarate versus other combination products: the DIFFUSE study. Combination Prod Ther. 2013;3(1):39-51. doi:10.1007/s13556-013-0003-9

40. Wu L, Van Holsbeke C, Mack P. Consistent lung delivery of inhaled triple ICS/LAMA/LABA combination using the co-suspension delivery technology: an in silico modelling study. Poster presented at: American Association of Pharmaceutical Scientists Pharmsci 360; 5 November 2019; San Antonio, Texas, USA. Available from: https://shwca.se/pharmsci2019. Accessed January 7, 2021.

41. Hatley RH, Parker J, Pritchard JN, von Hollen D. Variability in delivered dose from pressurized metered-dose inhaler formulations due to a delay between shake and fire. J Aerosol Med Pulm Drug Deliv. 2017;30(1):71-79. doi:10.1089/jamp.2015.1284

42. Thorsson L, Edsbäcker S. Lung deposition of budesonide from a pressurized metered-dose inhaler attached to a spacer. Eur Respir J. 1998;12(6):1340-1345. doi:10.1183/09031936.98.12061340

43. Chrystyn $\mathrm{H}$. Methods to identify drug deposition in the lungs following inhalation. Br J Clin Pharmacol. 2001;51(4):289-299. doi:10. 1046/j.1365-2125.2001.01304.x

44. Vos W, de Backer J, Schroeder J, Sommerville M, Dwivedi S, De Backer W. In-silico assessment of airway deposition using functional respiratory imaging for mono, dual and triple combination co-suspension metered dose inhaler formulations. Am J Respir Crit Care Med. 2016;193:A5811.

45. Hajian B, De Backer J, Vos W, Van Holsbeke C, Clukers J, De Backer W. Functional respiratory imaging (FRI) for optimizing therapy development and patient care. Expert Rev Respir Med. 2016;10 (2):193-206. doi:10.1586/17476348.2016.1136216

46. Taylor G, Warren S, Dwivedi S, et al. Gamma scintigraphic pulmonary deposition study of glycopyrronium/formoterol metered dose inhaler formulated using co-suspension delivery technology. Eur J Pharm Sci. 2018;111:450-457. doi:10.1016/j.ejps.2017.10.026

47. Israel S, Kumar A, DeAngelis K, et al. Pulmonary deposition of budesonide/glycopyrronium/formoterol fumarate dihydrate metered dose inhaler formulated using co-suspension delivery technology in healthy male subjects. Eur J Pharm Sci. 2020;2020(153):105472.

48. Darquenne C, Fleming JS, Katz I, et al. Bridging the gap between science and clinical efficacy: physiology, imaging, and modeling of aerosols in the lung. J Aerosol Med Pulm Drug Deliv. 2016;29 (2):107-126. doi:10.1089/jamp.2015.1270

49. Chrystyn $\mathrm{H}$. Methods to determine lung distribution of inhaled drugs could gamma scintigraphy be the gold standard? Br J Clin Pharmacol. 2000;49(6):525-528. doi:10.1046/j.1365-2125.2000.00215.x 
50. Newman S, Bennett WD, Biddiscombe M, et al. Standardization of techniques for using planar (2D) imaging for aerosol deposition assessment of orally inhaled products. J Aerosol Med Pulm Drug Deliv. 2012;25(Suppl. 1):S10-S28. doi:10.1089/jamp.2012.1Su4

51. Brand P, Hederer B, Austen G, Dewberry H, Meyer T. Higher lung deposition with Respimat Soft Mist inhaler than HFA-MDI in COPD patients with poor technique. Int $J$ Chron Obstruct Pulmon Dis. 2008;3(4):763-770. doi:10.2147/COPD.S3930

52. De Backer W, Devolder A, Poli G, et al. Lung deposition of BDP/ formoterol HFA pMDI in healthy volunteers, asthmatic, and COPD patients. J Aerosol Med Pulm Drug Deliv. 2010;23(3):137-148. doi:10.1089/jamp.2009.0772

53. Hirst PH, Pitcairn GR, Weers JG, et al. In vivo lung deposition of hollow porous particles from a pressurized metered dose inhaler. Pharm Res. 2002;19(3):258-264. doi:10.1023/A:1014482615914

54. Leach CL, Kuehl PJ, Chand R, McDonald JD. Respiratory tract deposition of HFA-beclomethasone and HFA-fluticasone in asthmatic patients. J Aerosol Med Pulm Drug Deliv. 2016;29(2):127-133. doi:10.1089/jamp.2014.1199

55. Leach CL, Kuehl PJ, Chand R, Ketai L, Norenberg JP, McDonald JD. Characterization of respiratory deposition of fluticasone-salmeterol hydrofluoroalkane-134a and hydrofluoroalkane-134a beclomethasone in asthmatic patients. Ann Allergy Asthma Immunol. 2012;108 (3):195-200. doi:10.1016/j.anai.2012.01.010

56. De Backer W, De Backer J, Vos W, et al. A randomized study using functional respiratory imaging to characterize bronchodilator effects of glycopyrrolate/formoterol fumarate delivered by a metered dose inhaler using co-suspension delivery technology in patients with COPD. Int J Chron Obstruct Pulmon Dis. 2018;13:2673-2684. doi:10.2147/COPD.S171707

57. Rabe KF. GFF MDI for the improvement of lung function in COPD a look at the PINNACLE-1 and PINNACLE-2 data and beyond. Expert Rev Clin Pharm. 2017;10(7):685-698. doi:10.1080/ 17512433.2017.13202180

58. De Backer J, Vos W, Vinchurkar S, et al. The effects of extrafine beclometasone/formoterol (BDP/F) on lung function, dyspnea, hyperinflation, and airway geometry in COPD patients: novel insight using functional respiratory imaging. J Aerosol Med Pulm Drug Deliv. 2015;28(2):88-99. doi:10.1089/jamp.2013.1064

59. De Backer LA, Vos W, De Backer J, Van Holsbeke C, Vinchurkar S, De Backer W. The acute effect of budesonide/formoterol in COPD: a multi-slice computed tomography and lung function study. Eur Respir J. 2012;40(2):298-305. doi:10.1183/09031936.00072511

60. De Backer LA, Vos WG, Salgado R, et al. Functional imaging using computer methods to compare the effect of salbutamol and ipratropium bromide in patient-specific airway models of COPD. Int J Chron Obstruct Pulmon Dis. 2011;6:637-646. doi:10.2147/ COPD.S21917

61. DeBacker W, DeBacker J, Verlinden I, et al. Functional respiratory imaging assessment of glycopyrrolate and formoterol fumarate metered dose inhalers formulated using co-suspension delivery technology in patients with COPD. Ther Adv Respir Dis. 2020;14:1-13. doi:10.1177/1753466620916990
62. Usmani OS, Capstick T, Chowhan H, Scullion J Choosing an appropriate inhaler device for the treatment of adults with asthma or COPD. 2017. Available from: https://www.guidelines.co.uk/respiratory/inhalerchoice-guideline/252870.article. Accessed November 19, 2018.

63. Price D, Chrystyn H, Kaplan A, et al. Effectiveness of same versus mixed asthma inhaler devices: a retrospective observational study in primary care. Allergy Asthma Immunol Res. 2012;4(4):184-191. doi:10.4168/aair.2012.4.4.184

64. Bosnic-Anticevich S, Chrystyn H, Costello RW, et al. The use of multiple respiratory inhalers requiring different inhalation techniques has an adverse effect on COPD outcomes. Int $J$ Chron Obstruct Pulmon Dis. 2016;12:59-71. doi:10.2147/COPD.S117196

65. Lavorini F, Fontana GA. Targeting drugs to the airways: the role of spacer devices. Expert Opin Drug Deliv. 2009;6(1):91-102. doi: $10.1517 / 17425240802637862$

66. Mahler DA. Peak inspiratory flow rate as a criterion for dry powder inhaler use in chronic obstructive pulmonary disease. Ann Am Thorac Soc. 2017;14(7):1103-1107. doi:10.1513/AnnalsATS.201702-156PS

67. Janssens W, VandenBrande P, Hardeman E, et al. Inspiratory flow rates at different levels of resistance in elderly COPD patients. Eur Respir J. 2008;31(1):78-83. doi:10.1183/09031936.00024807

68. Hakim A, Khan Y, Esteban I, et al. Low-dose budesonide/formoterol counteracts airway inflammation and improves lung function in chronic obstructive pulmonary disease. Am J Respir Crit Care Med. 2019;199(5):662-664. doi:10.1164/rccm.201808-1590LE

69. Pleasants RA, Hess DR. Aerosol delivery devices for obstructive lung diseases. Respir Care. 2018;63(6):708-733. doi:10.4187/respcare. 06290

70. ClinicalTrials.gov. A study to evaluate the effects of BGF and GFF on specific image based airway volumes and resistance in subjects with moderate to severe COPD. 2019. Available from: https://clini caltrials.gov/ct2/show/NCT03836677. Accessed May 22, 2019.

71. ClinicalTrials.gov. A scintigraphy study of PT010 in COPD patients (RD708/34000). 2019. Available from: https://clinicaltrials.gov/ct2/ show/study/NCT03906045. Accessed May 22, 2019.

72. Vincken W, Levy ML, Scullion J, Usmani OS, Dekhuijzen PNR, Corrigan CJ. Spacer devices for inhaled therapy: why use them, and how? ERJ Open Res. 2018;4(2):00065-02018. doi:10.1183/ 23120541.00065-2018

73. ClinicalTrials.gov. A study to assess the efficacy and safety of budesonide/albuterol metered-dose inhaler (BDA MDI/PT027) in adults and children 4 years of age or older with asthma (MANDALA). 2018. Available from: https://clinicaltrials.gov/ct2/show/ NCT03769090. Accessed May 21, 2019.

74. ClinicalTrials.gov. A study to assess the efficacy and safety of budesonide/albuterol metered-dose inhaler (BDA MDI/PT027) used 4 times daily in adults and children 4 years of age or older with asthma (DENALI). 2019. Available from: https://clinicaltrials.gov/ct2/show/ NCT03847896. Accessed May 21, 2019.

75. Battisti WP, Wager E, Baltzer L, et al. Good publication practice for communicating company-sponsored medical research: GPP3. Ann Intern Med. 2015;163(6):461-464. doi:10.7326/M15-0288

\section{Publish your work in this journal}

The International Journal of COPD is an international, peer-reviewed journal of therapeutics and pharmacology focusing on concise rapid reporting of clinical studies and reviews in COPD. Special focus is given to the pathophysiological processes underlying the disease, intervention programs, patient focused education, and self management protocols. This journal is indexed on PubMed Central, MedLine and CAS. The manuscript management system is completely online and includes a very quick and fair peer-review system, which is all easy to use. Visit http://www.dovepress.com/testimonials.php to read real quotes from published authors. 